\title{
A decision support tool for evaluating decision options for out-bound flight delays considering high-valuable passengers
}

\author{
Slavica Radivojevic ${ }^{1} \cdot$ Olaf Milbredt $^{1}$
}

Received: 3 February 2015 / Accepted: 16 November 2015 / Published online: 11 December 2015

(C) The Author(s) 2015. This article is published with open access at SpringerLink.com

\begin{abstract}
Introduction Though studies show that arriving on-time is the service characteristic most valued by the air passengers and passenger service coordinators are consulted in the operation disruptions, passengers rarely drive operational decisionmaking in the disruption management of an airline. Taking into consideration airlines' seeking the prevention of losing passengers' goodwill in situations where the level of service quality (SQ) performed is not as high as the promoted one, this research is focused particularly on an influence of delayed connecting (or in-bound) high-fare passengers on making decisions on onward delays. Operationally seen, connecting passengers are of a particular importance for airlines, since they are already involved in their operations-flow, while becoming in this way the third most important airlines' aspect of operations, succeeding aircraft and crew. On the other hand, exclusive travellers such as first class and elite-status, contracted corporate members, and business passengers are considered as the high-valuable passengers, who are enough (financially) worth to the airline, particularly for to be waited for if they are delayed in arriving with an in-bound flight. Based upon an examination made from the airlines' operational point of view
\end{abstract}

This article is part of Topical Collection on the Role of Information and Communication Technologies (ICTs) in Facilitating Global Research, Development, and Technology Transfer Cooperation

Electronic supplementary material The online version of this article (doi:10.1007/s12544-015-0189-x) contains supplementary material, which is available to authorized users.

Slavica Radivojevic

slavica.radivojevic@dlr.de

1 German Aerospace Center (DLR), Lilienthalplatz 7, 38108 Braunschweig, Germany and for determined prioritization strategy, a Decision Support System (DSS) tool, named DEVOTED DSS Tool, for use in the disruption management of the Airline Operation Control Centre (AOCC) is presented. For assisting the airline operation controllers in decisions on whether to delay the departure of out-bound flights in order to wait for arriving-delayed highfare passengers from an in-bound flight, an influence of these passengers' satisfaction on making decisions on onward delays, the passenger segmentation per flight, associated consequences in terms of the Level of Service (LOS) performed by the carrier and the one perceived by the passengers, as well as the accompanying costs are taken into account.

Methods The designed tool incorporates the key elements of Human-Centred Design (HCD) relying on a multi-criteria algorithm making-up its decision making process for evaluation of decision options and making suggestion. Being scenariodriven and knowledge-based the tool implements the airline prioritisation policies. Hereby, the level of service quality delivered by the air carrier and the level of service quality expected and perceived by the high-fare passengers are determined quantitatively by employing a created LOS-model which relies on the basic categorization rules of the Kano's quality model.

Results For testing of the tool, two scheduled airlines with two different prioritization strategies and operating on the same flight route between the same origin-destination airports (i.e. city-pairs) are taken. Though the testing is real-world data based, in order to expose a tangible aim and capabilities of the designed tool, the testing scenarios are constructed in such a way to reflect specific borderline operational situations, while emphasizing occurring conflicting decision key criteria. The tool output consists of two components - the LOS quality delivered by the carrier including the delay-costs ( $L O S$ Airline) and the level of service perceived by the high-fare passengers on both flights (LOS Passenger) - which are 
reflected on the user interface in form of two bars, each consisting of three colours indicating an option as good (green), neutral (yellow) or bad (red). Although the operation controller may take the opposite decision as recommended, the tool is enabled to display the evaluation of consequences of any decision made, while being visualized as a scale-value positioned somewhere on the three- colour-bar.

Conclusion Investigating the impact of a passenger-structure on decisions on onward-delays in the every-day flight operations execution, a decision support real-time tool, Delaying VIPs Oriented Decision Support System (DEVOTED DSS) was created, implementing (pre-specified) airline prioritisation policy in accordance with the rating of the high-fare passengers-classes importance. The decision solutions' consequences displayed in the designed form are practical in terms of user-friendly utilization of DEVOTED and are simple and easy to deal with, since being relieved of any digits, data and/or calculations. Aiming at accurately evaluating the impact of operational disruption-decisions on the highfare passengers, DEVOTED processes the LOS quality which is to be delivered to these passengers, SQ-attributes required/ expected by these passengers, number of passengers in each defined passenger-group and the ticket prices purchased, as well as expected costs. For the first time, an introduced juxtaposition of the in-bound and out-bound high-fare passengers of the same cabin-class within connecting flights has been employed as an influencing factor in the decision making process of the airline disruption management. When it is about to make the choice between a monetary benefit and the retention of the reputation of a reliable service provider, the use of the designed tool affords rather objective instead the still occurring intuitive decision making in such disruptions.

Keywords Quantifying level of service - DSS tool for airline disruption management $\cdot$ High-fare passengers in airline operations $\cdot$ Decision making at AOCC

\section{Introduction}

Though the survival of an airline is directly influenced by its operational and financial performance [1], under some specific circumstances and for saving its business reputation, marketing causes, or public policy reasons, the airline may take decisions on execution of its operations which can be opposite to the airline benefits or sometimes even with losses of revenue. With most conventional frill airlines, these specific operational decisions may be caused not only by unexpected external disruptive events, but also due to their own invalid operations and on request of different managerial departments such as commercial or public affairs department, aircraft technic, or ground handling staff. This has to be conducted within the every-day-operation execution at the Airline Operation Control Center (AOCC) (for more about AOCC, see: [2, 3]).

Whilst there is a requirement for such operations which could be rated as less beneficial or even disapproving for an airline, they may also be caused by delayed connecting passengers who are of the most (monetary) valuable profiles to the airline. Here fore, the service quality (SQ) level and passenger satisfaction should be more strongly taken into consideration. Similar indications were made in [4]. Though studies show that arriving on-time is the service characteristic most valued by passengers and customer service coordinators are consulted in the operation disruptions, passengers rarely drive operational decision-making [5]. On one hand, providing an on-time service to the travelers is important in striving not only for attracting financially valuable passengers who are highly sensitive to on-time reliability, but also for increasing passengers' satisfaction and loyalty, and therefore retention rate. On the other hand, as reliable and serious service providers, the airlines have to deliver to the customers the LOS quality which they have promoted within their published flight scheduling and ticket selling [6], which becomes especially apparent when the passengers have more than one flight-leg in their travelling from an origin to the destination airport.

Effectively managing passenger delays and schedule disruptions is critical to maintaining passenger loyalty and financial success which can be seen as a major challenge for the airlines [7]. To efficiently "exchange" transit passengers among flights at a hub, inbound-flights come in waves (i.e. banks) followed by the waves of outbound-flights [8]. Having in mind that connecting passengers are almost three times more likely to be disrupted than originating ones, by missing their connecting flights they will be often re-accommodated on their best possible, but rather on the best available itineraries, assuming that each recovery itinerary must operationally be feasible while all its flight-legs operated [7]. This is made by applying the Passenger Recovery Plan which is based on the necessity to reassign disrupted passengers to alternative itineraries, commencing at the location after their available times and terminating at their destination or a location nearby [9]. Enabling also the minimum connecting time (MCT) achievable for getting the followup-flight(s), airlines may apply various policies for the passenger recovering such as: (i) unranked or first-disrupted-first-recovered policy, or (ii) ranked where the passengers are recovered in order of decreasing fare-class-value (the most valuable first), or in order of decreasing FFPs-status (FFP-members first) [7].

On one hand, exclusive travellers such as first class and elite-status, contracted corporate members, and business passengers are considered as the high-fare (i.e. valuable) passengers, who are financially highly worth to the airline [10]. On the other hand, operationally and technically seen, connecting inbound (and not only the high-valuable) passengers are of 
particular importance for airlines, since they are already involved in their operations-flow becoming in this way the third most important airlines' aspect of operations, succeeding aircraft and crew. Differing from two other kinds of delaying passengers, i.e. self-late and late-due-to-airport facilities, the arriving-delayed connecting passengers perceive another handling procedure (and accordingly, an importance value) in the airline operation execution.

This research examines to which extent the disruptive/ irregular events such as missed and delayed connections may affect the airlines' high valuable passengers' satisfaction, if taking into consideration airlines' seeking the prevention of losing passengers' goodwill especially in the situation where the level of service quality (SQ) performed is not as high as the promoted one. In focus is particularly an influence of delayed connecting (in-bound) high-fare passengers on making decisions on onward delays. Recognizing how much the passengers give an importance to the free air travel miles as well as experts' emphasizing that it is more expensive (up to 5 to 10 times [11]) to recruit a new customer than to retain an existing one, the main interest is on learning and understanding the role of the passenger structure i.e. passenger segmentation per flight and its importance in decisions on making departuredelays, focusing on how this importance may impact decisions on delays of affected flight(s) in relation with SQ performance and associated costs.

To investigate these issues, this research first develops a LOS-model for both the airline and the passengers to integrate it then into the designed support tool. Relying on the basic categorizations of the Kano's model of quality (described in [12]), the created LOS-model is combined with a juxtaposition made of the segmentation of high-valuable passengers per flight (i.e. per ticket/cabin-class) for to be implemented as one of the main inputs in the designed support tool.

Hereby, the term high-valuable passengers denotes the passengers of the highest importance to the airline who are enough worth to be waited for, even if it might cause some delays on departure and adding costs. This aligns with the claim of Castro and Oliveira [13] that of a great importance in some decision making situations appears to be "who" the passengers on one flight are. Referring to their economic value to the airlines, those passengers' flying status can be acquired by the highest ticket price purchased or as golden/silver/senior-card status ownership (i.e. first-class), or becoming a Frequent Flyer Program member, as well as a person with a special service treatment (VIP) or a commercially important one (CIP).

A knowledge- and scenario-based decision support tool, Delaying VIPs Oriented Decision Support System DEVOTED DSS, was created as computer-based interactive supporting system to assist the airline operation controllers in making decisions on whether to delay the departure of an outbound flight in order to wait for the delayed arriving connecting high-valuable passengers from an in-bound-flight. Within the implemented process of making decisions on this kind of disruptions, facilitated is a choice between two main (usually conflicting) criteria: monetary benefits and retention of reputation of a reliable and serious service provider. The two main outputs of the DEVOTED tool are: LOS Airline defined as SQ level performed to the passengers and the operating profitability, and LOS Pax defined as passengers' satisfaction level achieved with the particular airline's service delivered (i.e. decision made). The decision consequence Cost consists of overhead costs that arise from decisions on waiting or not waiting at the departure and becomes the third output of the DEVOTED tool.

Emanating from the particular decision made, the values of the tool-outputs are displayed on the coloured bar consisting of a red, yellow, and green field which represent: a bad, medium or indifferent, and good performance.

Aiming predominantly at monitoring of decision solutions and their quantitative and qualitative consequences, the designed tool may enable more awareness of controllers within the decision processes, though not intending to replace them. This may be particularly apparent when the disruptive events directly impact flight itineraries of the high-value passengers, where the final decisions need to be made in particular by humans. Contributing also to affording rather objective instead still in practice occurring intuitive decisions [14] when dealing with such kind of disruptions, the supporting tool was designed respecting the key elements of Human-Centred Design (HCD) [15]. It incorporates the user's perspective considering the disruption situation conditions which if not solved timely it may expand through the carrier's network impacting predominantly the downstream flights, as well as the organizational requirements such as an airline's prioritisation policy.

\section{Related work}

Theoretical framework for design of the tool is divided into three main topics: (1) Airlines' recovery plan affecting the passengers and recovering costs, (2) Decision making process at the AOCC and its application, and (3) Relationships between an air carrier's SQ delivered and the level of the passengers' satisfaction with the service perceived.

\subsection{Airline recovery plan considering the passenger-recovery}

In the research work on airline's operations recovery, passengers are considered primarily as an integrated problem included either within an aircraft-recovery and/or crew-recovery solutions, since at most large airlines the resource-recovery hierarchy order is strongly defined and followed when 
disruptive events occur: firstly the aircraft-recovery is to solve, then crew-recovering plan, ground operations problems, and lastly the implication of these recovery decisions on passengers inconvenience will be considered as emphasized by [2], and done by $[5,7,16,17]$.

While [3] contributed by giving valuable definition of the airline disruption management, studies $[4,13]$ examined the operational recovering in the airline disruption management including for the first time quantifying of the "quality operational costs" as costs of delaying or cancelling a flight from the passenger point of view, by defining the existing passenger profiles and applying a delay cost for each passenger in each profile.

The Westminster Research, reported by Cook et al. [18], focuses on delay-costs to the airline caused by the Air Traffic Flow Management (ATFM). It was the first study which recognized two kinds of passenger-delay costs differentiating them into "hard"-monetary measurable and "soft"- as hardly monetary measurable ones. Although this report does not consider delays for passengers nor in arriving or in transfer, it gives a valuable insight into the fractional classification of possible sources of passenger costs. In the authors' following work [19], the passenger "soft" delay costs refer to a loss in revenue of an airline as a result of an experienced delay.

Cook and Tanner in [20] represented a full gate-to-gate model which includes re-accommodation of disrupted passengers with missed connections due to delays. Respecting the cost minimization, disrupted passengers are re-allocated regardless of their ticket and/or cabin class, respecting the total seat space available while excluding possible up-/down-grading. Applying flight and passenger prioritization scenarios, their cost estimations include also the passenger Value of Time (VOT) separately estimated for the passengers with the defined flexible and inflexible tickets, both quantified as a function of delay at the final destination. Since the passengers with the "flexible tickets" considered in their study refer to the highest ticket fares owners correspond to the high-valuable passengers examined in this paper, their so estimated VOT has been adopted.

\subsection{Decision making process at the AOCC}

For establishing the suitable framework for the tool development in this study, gaining an insight into the driving attributes of the highly complex relationship between humans (operation controllers) and technology used in the decision making processes (tools) at the AOCC was necessary.

a. Castro and Oliveira [21] identified the current tools in use classifying them into Database Query Systems, Decision Support Systems, and Automatic or Semi-Automatic Systems, according to the background processing service level they provide, while concluding that final decisions in any of them depend on the human operators/supervisors. b. Some deeper understanding of decision making processes at the AOCC, as well as the trend and the way of dealing with irregularities common in use at scheduled airlines today were provided by the study observations demonstrated by Bruce [14]. The study offered for the first time for public use a deeper insight into the highly complex human decision making processes in this specific area of the airline (especially irregular) operations.

In any case, these kinds of disruptions cannot be fully automated, while humans determine the level of disruptionseriousness and neediness of an action i.e. whether to be undertaken (or not).

Perhaps there exist some in-house-developed tools for processing and managing high-fare passengers when dealing with such irregular/disruptive events, thus being fed by airlines' own database and therefore not necessarily available for research and public use.

\subsection{Relationship between carrier LOS and the passengers' satisfaction}

Though the SQ of a carrier is widely used to be seen in terms of disharmonised characteristic-combinations, they can be classified into several different groups of SQ-attributes. Common and the most important aspect of the SQ measure of an airline is its reliability or on-time performance. The focus hereby was to identify and understand the passengers' needs and requirements in order to meet them satisfactorily and optimally for both service-providers and customers.

Doganis [6] has identified five key variable factors that influence customer behaviour in making and taking travel decisions, whereby more important is, that the travellers' choice between the airlines is different within each of the given travelling categories which are defined as: price factor; schedule-based factors (such as frequency, connections, punctuality); comfort-based factors (such as aircraft-type airline lounges, ground/terminal service); convenience factors (such as distribution, capacity, and seat-availability), and image factor (such as FFPs, promotion, advertising, market position). How these various product features will be combined in order to meet customer needs in their different market segments, each airline has to decide for itself.

IATA Corporate Air Travel Survey [22] observed the key determinants that influence business passengers' airline choice including for short-haul flights: FF-Programs, convenient departure and arrival times, as well as punctuality of flights, while for long-haul flights: FF-Programs, non-stop flights, and seat-comfort.

Dissatisfaction with the service quality (SQ) delivered can cause not only the passengers' dissatisfaction generally, but also may affect their intention to switch to another airline, while SQrequirements that lead to passengers' satisfaction influence building their loyalty. This confirmed the examination [23] 
predicating how the overall satisfaction with the perceived carrier's SQ positively influences the buyer's loyalty. The importance of the relationship between the SQ and the passengers' satisfaction with it can be better understood if taking into consideration that frequent travelers account for $80 \%$ of the airline passenger revenue, confirming that the frequent flyers generally travel more than 10 times per year, or approximately every 4 5 weeks on average [24], and that all connecting flights are constrained with the risk of misconnections and discomfort.

\section{Research approach}

\subsection{Operational Situation and Research Objective}

This research is focused on situations where airline operation controllers are required to take a decision whether to delay the out-bound flight in order to wait for the delayed in arriving connecting high-fare passengers of an in-bound flight. Such an every-day flight operational situation is illustrated in Fig. 1 showing the out-bound flight $\mathrm{F} 2$ which should depart from the airport B taking with some connecting-passengers from the delayed in arriving in-bound flight $\mathrm{F} 1$.

Generally, if the airline controllers decide to depart the outbound flight without the arriving-delayed passengers, these passengers will be offered a recovery program in terms of rebooking, re-accommodation, as well as, if needed, compensation. However, risking the possible losing of these passengers' goodwill due to their dissatisfaction with the service quality experienced. Most of airlines nowadays use some kind of ruleof-thumb when they are evaluating the impact of the decisions on passengers, others just assign a monetary cost to each delay minute [4]. Hereby, the passenger recovery strategy mostly depends on the airline's network and its business plan, while losing passengers' goodwill with a consequence of their switching to another airline can also be dependent on the current situation on the particular market (i.e. if there is one or more competitor(s) operating the same route/city-pair).

Considering the passenger-configuration on both flights in the illustrated situation, there are three passenger groups being divided according to their origin-destination travel position:

- Pax-Group I: delayed in arriving connecting high-fare passengers (F1)

Fig. 1 Simplified connecting flight: departing out-bound flight (F2) at the airport B and an inbound flight (F1) which is delayed in arriving
- Pax-Group II-1: departing passengers (from B) who will end their trip at airport C (F2)

- Pax-Group II-2: departing passengers (from B) who do not end their trip at airport C (F2)

Taking into account the accompanying consequences of each decision option, the LOS for both the carrier and the passengers is modelled. The model framework relies on the basic categorization rules of Kano's quality model (see [12]) applied to the determined SQ-attributes. The service quality attributes-requirements of both the carrier and the passengers have been taken from the relevant literature findings (see Section 2.3). These are modelled using a created extension of Kano Model of quality for each of the three passengergroups (as given above). The purpose of the developed LOS-model is to show how well the chosen qualityrequirements (i.e. the required SQ-needs) have been satisfied (i.e. performed by the carrier) at the moment of the decision making.

The LOS-model for both the airline and the passengers is implemented into the proposed decision support tool. The framework for the tool's solving-algorithm is shown in Fig. 2.

The illustration displays the tool setup and its framework being dependent on the flight-information (updates), occurring air traffic conditions, the airline and airport current operations flow, as well as prioritisation policy of the operating airline.

Commonly, the airline controllers can subjectively incorporate the passenger flow issues (such as connectivity, passengers' goodwill and volume of traffic) into the decision process by resolving irregularities. Since the quality of their decisions are not displayed, they could not, in some cases until aftermath, find out that actions, such as to delay or cancel flights, were unnecessary decisions [25]. The proposed tool takes into consideration the above shown factors as most influencing on the decision making process for a particular flight which may tend to expand to one disruptive flight if not handled timely, potentially impacting also the downstream flights.

\subsection{Delaying VIPs oriented decision support system - DEVOTED DSS tool}

When making decisions, airline operation controllers are required to consider some given priority rules. These are predetermined by the airline policy for to be respected within
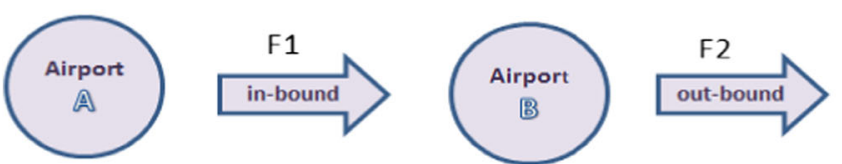
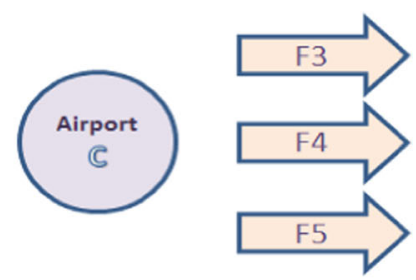


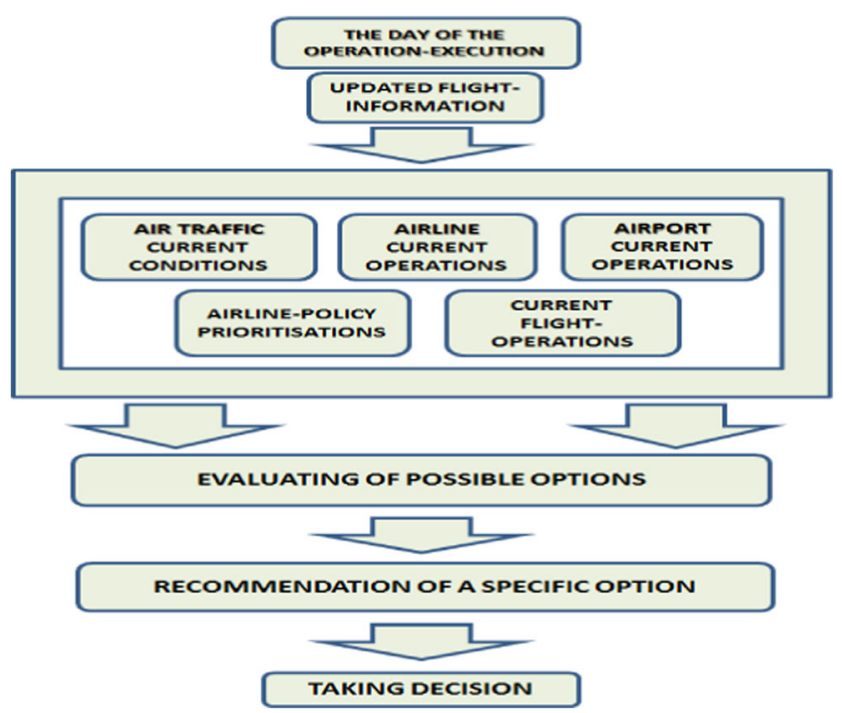

Fig. 2 Architecture of the designed supporting tool

the decision making process. The airline priority rules depend on determined operational, tactical, strategic and economic goals, as well as constraints of the airline's businesses, because the market-segmentation strategy is unique to the airline, reflecting the specific and local conditions [26]. This can however even vary for the same route (city-pair) in the everyday operations, but also based on requirements of the airline's managerial departments due to operational and/or tactical updates.

DEVOTED implements (as described above) the prespecified airline prioritisation policy in accordance with the rating of passenger-classes importance and therefore the LOS which is to be delivered to these passengers, SQ-attributes required by these passengers, number of passengers in each defined passenger-group, and the ticket prices purchased, as well as expected costs as its main influencing decision factors. The processing of the tool relies on the flight plan updating, well known Minimum Connecting Time (MCT) ${ }^{1}$ of the connecting airport and the maximal allowed delay for the particular flight/aircraft, the passenger segmentation per aircraft/flight and the graduation of their importance to the airline. Serving the purpose of both, evaluation of possible option scenarios available at the moment of decision making and recommendation of a specific solution, the processoriented tool comprises of a multi-criteria algorithm of which each component represents for the airline an operationally achievable option when dealing with such kind of disruptions. Its mathematical background relies on decision-functions determined by parameters and variables, being denoted by quantities chosen before any flight has been scheduled (parameters) and quantities depending on each flight (variables). These are:

\footnotetext{
${ }^{1}$ Published by airport authorities, MCT is the shortest feasible time required for passengers/baggage to connect between flights at an airport.
}

\section{- Parameters}

(1) Airline Prioritisation Policy (APP), describes the importance of the two factors:

- LOS to the passengers (APP1)

- Operating profitability (APP2)

These parameters can be given by a fraction of 1 .

(2) Airline's passenger importance graduation, denoting the pairwise (for in-bound and out-bound flight) importance ratio of the passenger cabin classes

(3) Ticket prices purchased per cabin-class(es)

(4) Expected costs (e.g. passenger-recovery, compensations, compensations according to EU Reg. (EC) No 261/2004, the Value Of Time (VOT))

- Variables: Number of passengers:

- On in-bound and out-bound flights, per ticket-/cabinclass:
a) VIP/CIP-passengers (VIP)
b) First class passengers (1.C)
c) Business passengers and frequent flyers (BUS + FFP)

The functions are constructed to consider all high-valuable passengers (on both flights) in a juxtaposition, whereby each cabin-class is separately taken into account including current flight position of the passenger (if being on an inbound or outbound flight). Hence, the input of DEVOTED DSS Tool consists of 14 different quantities, i.e. parameters and variables, covering a wide variety of different operational situation possibilities, while each decision option generates three output-parameters:

(i) The level of service quality perceived by the passengers (on both considered flights)

(ii) Level of service quality performed by the airline

(iii) Expected overhead costs that may occur.

Respecting the key rules of $\mathrm{HCD}$, the outputs of DEVOTED are reflected on the user interface in form of a three-color-bar being entirely disburdened from digits and/or calculations becoming simple and easy to deal with. Resulting values of the SQ performance and satisfaction level achieved are shown as good (green), medium/indifferent (yellow), or bad (red), as displayed in Fig. 3. This means that a satisfying SQ-performance and/or LOS perceived by passengers will be shown as the output value lying in the green field, if not satisfying or bad - in the red one. 


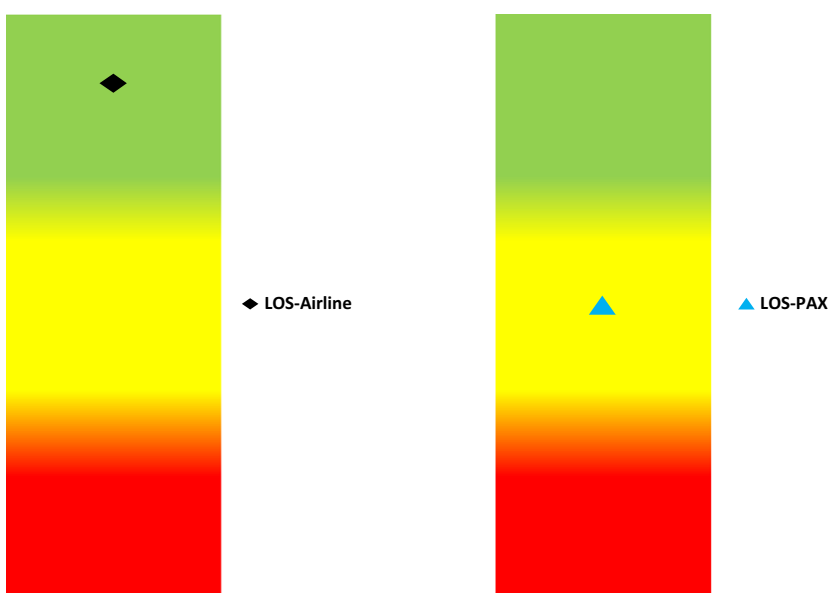

Fig. 3 The DEVOTED DSS tool outputs

The tool main output components are named LOS Airline (consisting of two components: on-time performance and operating profitability) and LOS Pax (showing the satisfaction level achieved by the high-valuable passengers) considered for both flights, in-bound and out-bound.

\section{Application of the DEVOTED DSS tool}

In order to demonstrate a tangible aim of the designed tool, the testing scenarios were constructed to reflect specific borderline operational situations while emphasizing occurring conflicting non-quantifiable key criteria. They comprise of several chosen operational situations which decision solving solutions are directly affected by varying the following influencing criteria:

(1) the defined Airline Prioritisation Policies (APPs) and the relation among them,

(2) the graduation of importance of each passenger-group to the airline,

(3) the segmentations of the high-valuable passengers and their distribution on both flights,

(4) the high-fare ticket prices and consequently the high-fare ticket revenue per flight.

The testing is based on real-world data belonging to the statistical data bank - property of the institute where this research has been completed. The two examined airlines, named Airl and Air2, are legacy or full service network carriers differing in their prioritisation policies and their statuses at the connecting airport B (see Fig. 1). Ticket prices are taken firstly in terms of average prices and then adjusted to the highvaluable cabin-classes in accordance with the recommendations by IATA worked up in [6].

Excluding the economy cabin-class since this is not subject to this research, the seat-configuration and accordingly the passenger-segmentation per flight/aircraft taken for the testing are based on a typical seat-configuration of an A340-fleet aircraft for the flight F1 between the airports $\mathrm{A}$ and $\mathrm{B}$ and an A330-fleet aircraft for the flight F2 (between B and C), that are usually flown on the examined flight destination by the examined airlines.

The airline Airl is assumed to put more weight on operating profitability (i.e. generating revenue) than on passengers' SQ perception, expressed in a partition of 10 vs. $90 \%$.

The airline Air2 is assumed to put more weight on the LOS to the passengers than on operating profitability, being expressed in a partition of 80 vs. $20 \%$ (see Section 3.2, parameter under (1)).

Employed tool decision function implies two decision issues - level of service delivered to the passengers and operating profitability - which it evaluates, whereby, if the resulting function value falls below zero, the tool recommends not waiting, while for a value above zero - waiting solution. For this paper purposes, 2 of the testing scenarios are presented in Tables 1 and 2 .

In accordance with Section 3.2, input data for each scenario in both tables above are given as variables (a)-(c) by columns 1-3, while parameter (3) by column 4 .

In Scenario 1, the importance ratio of VIPs to the 1.classpassengers is taken to be 6.7 , while the one of the 1.classpassengers to the (BUS + FFP) is 1.4 (see Section 3.2, parameter under (2)), while in Scenario 2, the importance ratio of VIPs to the 1.class-passengers is taken to be 1.3 and the importance ratio of the 1.class-passengers to the (BUS + FFP) 1.8 .

Computed for both scenarios and airlines, the main tool decision inputs are presented in Table 3.

Presented input data are evaluated by the DEVOTED decision function making a recommendation (whether to wait or not for the arriving high-fare passengers), being dependent on the availability of the passenger-recovery plan for the case of the decision solution not waiting, determining in this way the tool-output component, LOS Airline. The other output-component, LOS Pax, is calculated from the created LOS model for obtaining passengers' satisfaction level, taking into account each high-fare passenger of each cabin-/ticket-class individually and on both flights considered.

Table 1 Scenario 1

Connecting Flight VIPs 1.class-Pax BUS + FFPs Ticket-Revenue (EUR)

\begin{tabular}{lllll}
\hline Pax-Group I & 2 & 1 & 16 & $53,371.00$ \\
Pax-Group II-1 & 1 & 1 & 58 & $219,920.00$ \\
Pax-Group II-2 & 0 & 1 & 5 & $23,150.00$ \\
\hline
\end{tabular}


Table 2 Scenario 2

Connecting Flight VIPs 1.class-Pax BUS + FFPs Ticket-Revenue (EUR)

\begin{tabular}{lllll}
\hline Pax-Group I & 1 & 1 & 44 & $169,660.00$ \\
Pax-Group II-1 & 2 & 3 & 20 & $70,621.00$ \\
Pax-Group II-2 & 6 & 4 & 21 & $96,238.00$ \\
\hline
\end{tabular}

However, the final decision and its consequences will depend on the operation controller's decision on whether to follow the tool-recommendation or to take the opposite solution, which the DEVOTED tool additionally offers. Applying the mapping function, the tool-outputs (in both cases, if following the recommendation and if not) are displayed on the user interface for each airline as shown in Figs. 4 and 5. Both outputs, LOS Airline and LOS Pax, are displayed for each airline and each case in both scenarios on a single 3-color-bar.

Figure 4 shows the tool-outputs for Airl and Fig. 5 for Air2, presenting results of both decision possibilities in each scenario: left-handed 3-color-bar per scenario for the case if the airlines follow the tool-recommendations while achieving a higher service quality performance, and, the right-handed 3-color-bar per scenario for the case the airlines take the opposite decisions, whereby the toolrecommendations remain in accordance with defined airlines' prioritization policies.

\section{Discussion}

In both presented scenarios, the tool recommends to each airline the one solution which is in accordance with the defined APP of a particular airline ensuring therewith its better SQ-performance, while recommended solution remains operationally achievable for the airline.

Though there are the same sizes of the 3 passengergroups observed for both airlines, referring to one of the main criteria - passenger cabin-class importance criteria, the VIP-importance-value is much higher in Scenario 1 than the one in Scenario 2 and the ticket prices (per same cabin- class) for the arriving flight are lower than for the departing flight. In Scenario 2, the ticket prices per same cabin-class for the arriving flight are taken to be higher than for the departing (outbound) flight (see Tables land 2) to provoke an influence of this input on the tool's decision process.

In Scenario 1, DEVOTED DSS Tool recommends to both airlines - not waiting. However, this conclusion may appear almost obvious and predictable, since:

- the decision making process of Airl is mostly impacted by the operating profitability criterion, and the ticket prices on the out-bound flight are higher (by around $35 \%$ ) as well as number of these highfare passengers than on the in-bound flight. This will accordingly lead to the decision solution not waiting, since the ticket revenue gained on the departing flight is higher than the one gained on the arriving flight.

- According to Fig. 1-left side, if Airl follows the tool recommendation, it achieves much higher SQ performance (in the green field), than in the opposite decision (to wait), while the passengers' satisfaction just minimally differs in both options (in the yellow);

- the decision making process of Air 2 is mostly impacted by the LOS delivered to the passengers within the given passengers segmentation: there is only 1 VIP-passenger more in the arriving-group of high-fare passengers (paxs) which size (19) is around three times smaller than the departing high-valuable passenger group (66 paxs). Therefore, confronting 1 VIP-more and 16 (BUS + FFPs) on the arriving flight with 1 first-class and 63 (BUS + FFPs) paxs more on the departing flight, leads to the decision not waiting.

- As Fig. 2 shows on the left side, following the toolrecommendation also Air2 improves its SQ performance, whereby in the opposite solution (to wait) the overall passengers' satisfaction would be much higher, however by worsening its SQ level.

In Scenario 2, the ticket revenue gained on the inbound flight is slightly higher than on the outbound one. The DEVOTED DSS tool makes different recommendations to the airlines:

Table 3 Two key decision inputs computed for each airline in each scenario

\begin{tabular}{|c|c|c|c|c|}
\cline { 2 - 5 } \multicolumn{1}{c|}{} & \multicolumn{2}{c|}{ Scenario1 } & \multicolumn{2}{c|}{ Scenario2 } \\
\cline { 2 - 5 } \multicolumn{1}{c|}{} & LOS to the Paxs & APP1+APP2 & LOS to the Paxs & APP1+APP2 \\
\hline Air1 & 1,138235294 & $-0,579639561$ & 0,996240602 & 0,002934245 \\
\hline Air2 & 1,138235294 & $-0,157665262$ & 0,785714286 & $-0,034790211$ \\
\hline
\end{tabular}



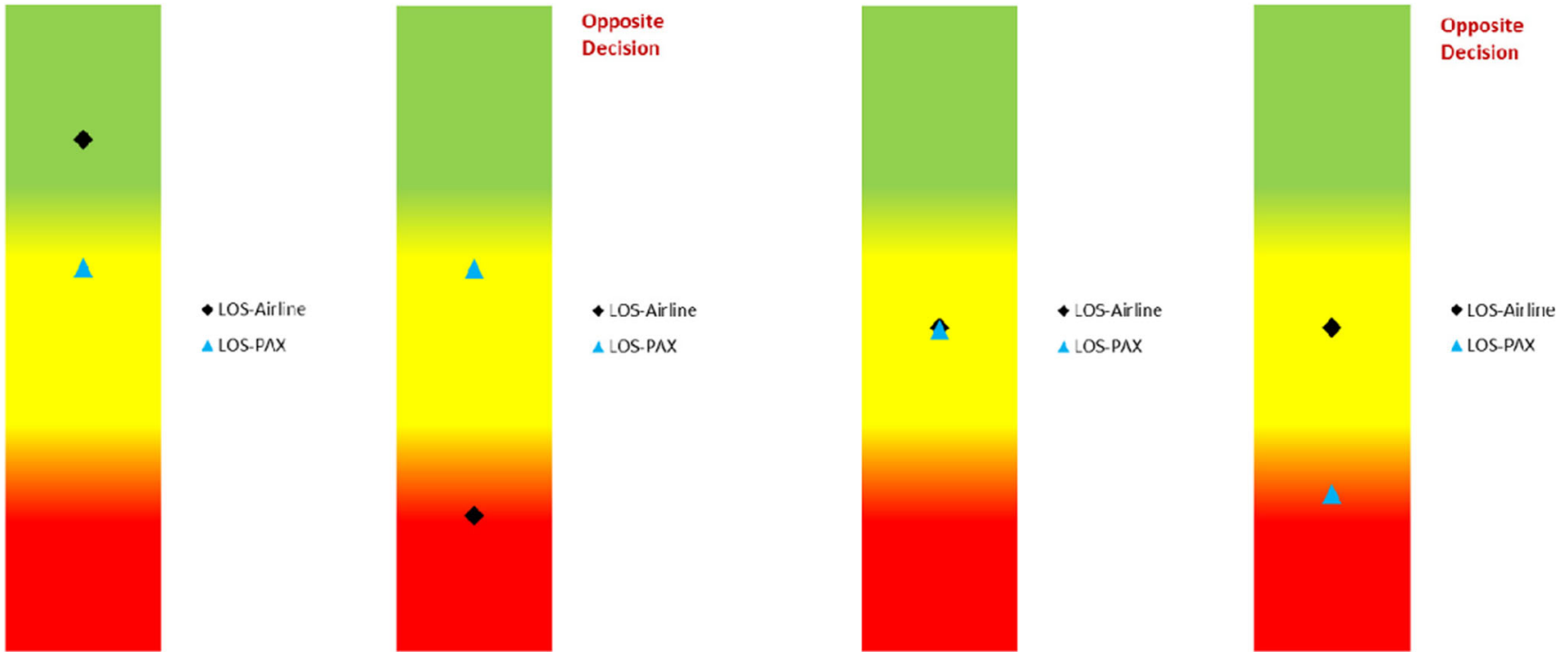

Fig. 4 DEVOTED-Output of Airl: Scenario1 (left-hand) and Scenario2 (right-hand)

- to Airl - to waiting: since the in-bound flight gains somewhat higher ticket revenue than the outbound flight, for Airl it is worth waiting for its delayed arriving high-valuable passengers. According to Fig. 4 - the right side, the airline achieves a higher overall passengers' satisfaction level if it follows the tool-recommendation, while in the opposite solution (not waiting) it would achieve minimally worse SQ-performance but with a much higher dissatisfaction level of all passengers (LOS Pax in the red field);
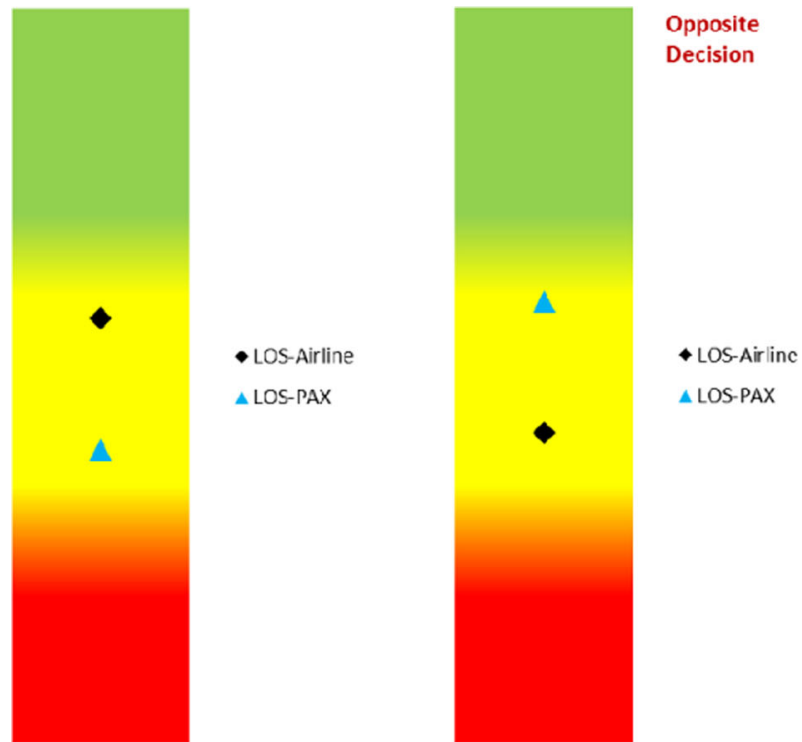

- to Air2 - to not waiting: since for this airline is worth departing with no delay and without having its in-bound delayed passengers on board (by having passenger-recovery available). In the recommended solution Air2 would achieve a better SQ performance, which is shown in Fig. 5 (righthanded) as its LOS Airline is placed in the bar's green field. In the opposite solution (waiting), although the overall passengers' satisfaction would be higher (since the in-bound passengers would be very satisfied to be waited for, in spite of their

Fig. 5 DEVOTED-Output of Air2: Scenario1 (left-hand) and Scenario2 (right-hand)
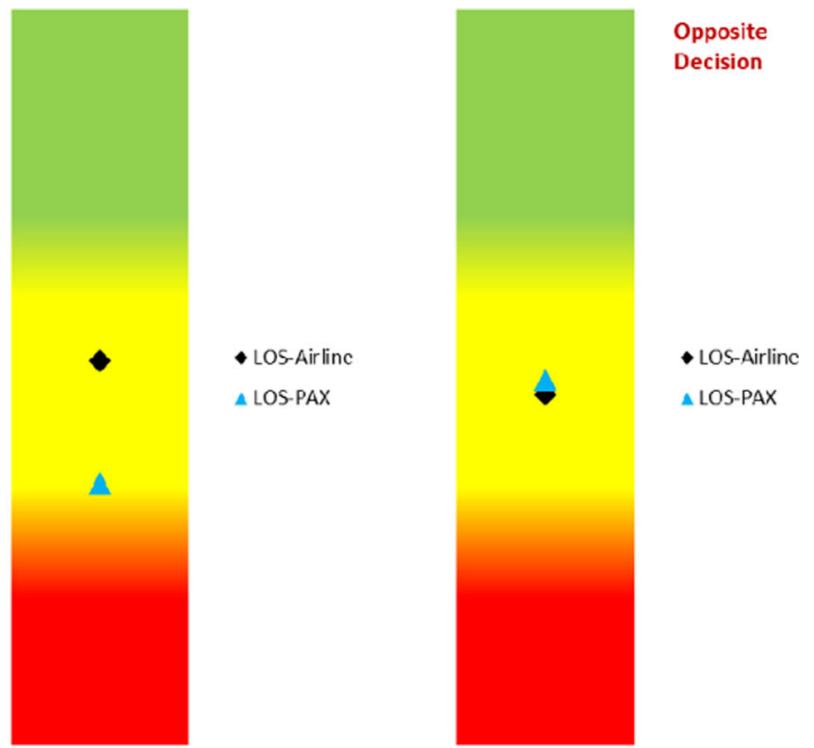
own arriving-delay), however by achieving a worsen SQ perform.

Thus to be mentioned, all testing scenarios (and the two presented above) are specific random operational situations constructed to show required multi-criteria issues which must be evaluated in a very limited decision making time when it is about to deal with such kind of decisions.
Respecting the given airline prioritization policies for Airl and Air2, for finding out at which amount of passengers of the particular cabin-class the tool's decision function will change its recommendation from not waiting into the waiting solution, the number of for that "needed" in-bound (connecting) high-fare passengers of each cabin-class separately was varied. Results are shown in figures below, for each scenario and each passenger-class separately.

\section{Results Scenario 1}

\section{For VIP-Passengers (VIP):}

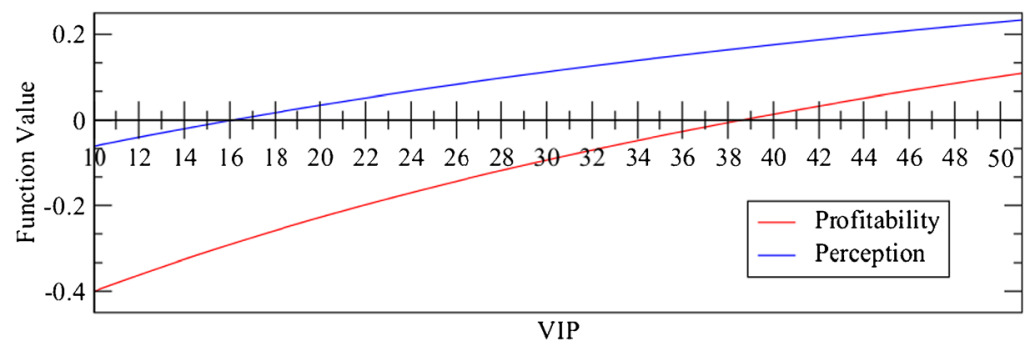

For the First-class Passengers (1C):

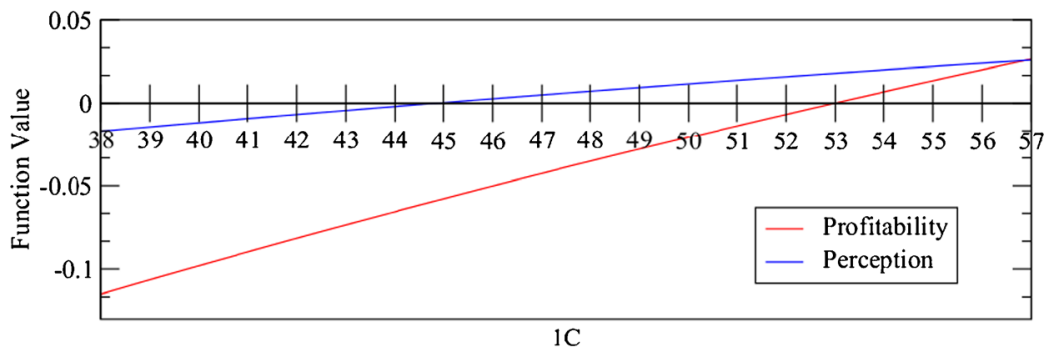

For Business passengers (BUS) and Frequent Flyers (FFPs):

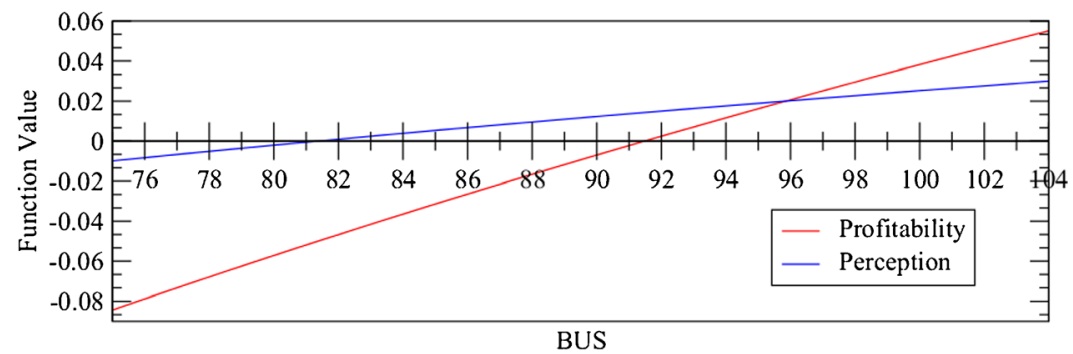

As presented in the figures above, the results obtained in Scenario 1 show that the decision-function-value will change its recommendation from not waiting into waiting solution when: 
- in the case of Airl, on the arriving in-bound flight there can be found: 39 VIPs, or 53 first-class, or 92 business passengers and/or frequent flyers;
- in the case of Air2, on the arriving in-bound flight can be found: 16 VIPs, or 45 first-class, or 82 business passengers and/or frequent flyers.

\section{Results Scenario 2:}

For VIP Passengers (VIP)

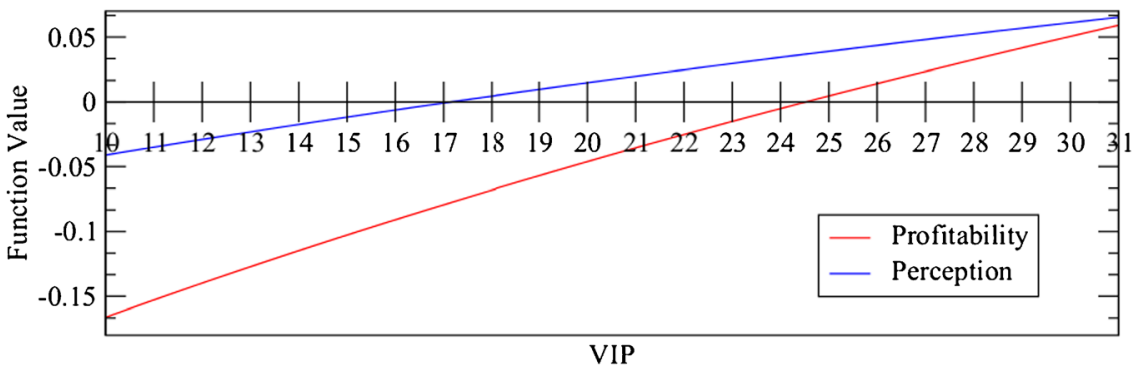

For First-class Passengers (1.C)

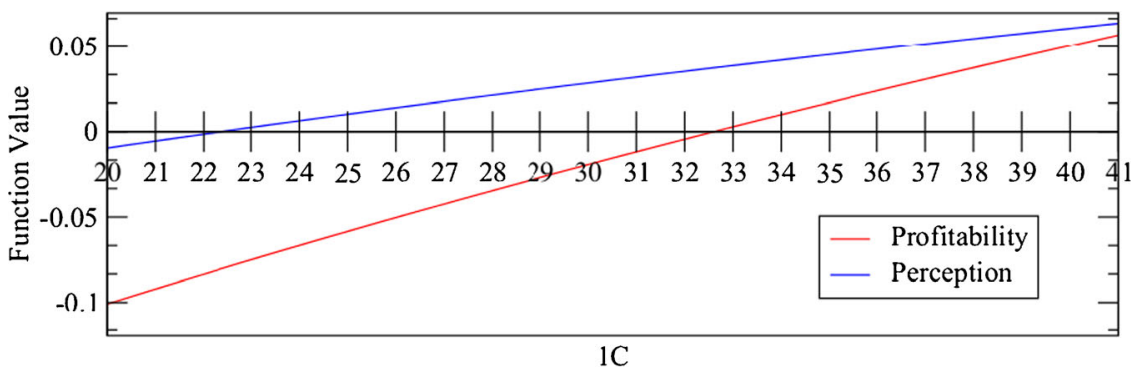

For Business passengers (BUS) and Frequent Flyers (FFPs)

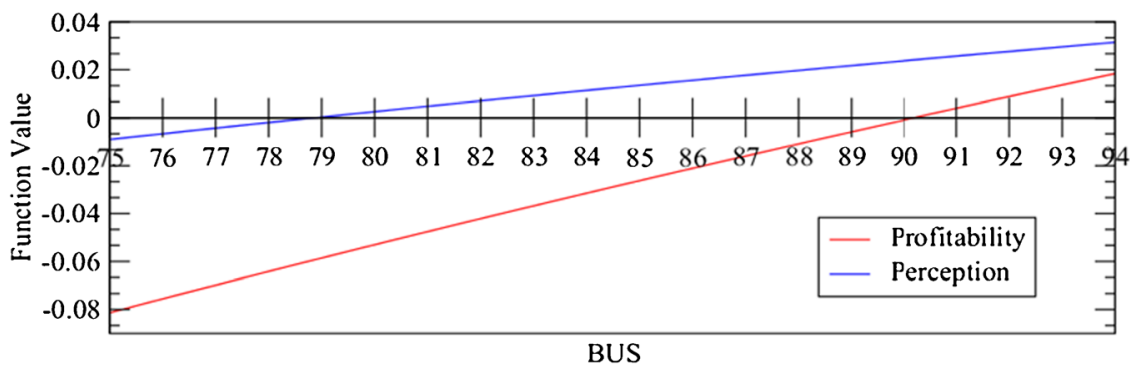

As figures above show, results obtained in Scenario 2 display that the decision-function-value will change its recommendation from not waiting into the waiting solution when:

- in the case of Airl, on the arriving in-bound flight can be found: 25 VIPs, or 33 first-class, or 90 business passengers and/or frequent flyers;

- in the case of Air2, on the arriving in-bound flight can be found: 17 VIPs, or 23 first-class, or 79 business passengers and/or frequent flyers.

\section{Conclusion}

Exploring particularly the influence of delayed connecting high-fare passengers on making decisions on onward delays in the carriers' striving to deliver a better service quality to these passengers, the passenger segmentation per flight and the associated consequences in terms of the LOS performed by the carrier and the one perceived by the passengers have been taken into account. The research focus was on an identification of a causality of the high-valuable or premium (i.e. VIPS, 
FFP- and Golden-/Silver-/Platinum card members, firstclass and business passengers) passengers' importance to the airline and a conceivable influence of this importance on decisions on delays within its operation execution and disruptive events. Based upon an examination made from the airline's operational point of view with a determined prioritization strategy, a process-oriented real-time decision support tool - DEVOTED DSS - was designed.

Research literature argues how most airlines nowadays use some kind of rule-of-thumb when they are evaluating the impact of decisions on the passengers, while others just assign a monetary cost to each minute of delay and evaluate the solutions taking this value [4]. DEVOTED DSS has been designed to aim at accurately solving this problem resulting in enabling the airline operation controllers an assessment of these important performance issues. The final decisions remain in this way always in the responsibility of the operation controller (i.e. airline), though with the possibility of getting saved each decision made together with the accompanying consequences for the statistical and analysis purposes of the airline's businesses.

The tool outputs represent the consequences of the decision made. Displayed in the designed form, they are practical in terms of user-friendly utilization of DEVOTED DSS and are simple and easy to deal with. The tool output is visualized as a scale-value positioned somewhere on the three-colour-bar being relieved of any digits, data and/or calculations, showing the final values of the level of the carrier's SQ achieved and the one perceived by all high-fare passengers.

For the first time a confrontation of the in-bound and outbound high-fare passengers of the same cabin class within connecting flights as an influencing decision making factor in the airline disruption management has been introduced and investigated. This is done by using a juxtaposition of the high-valuable passengers from an in-bound flight with the high-valuable passengers of the same cabin-class of the outbound flight, respecting their segmentation per flight, their ranking-priorities, and their determined importance values.

When it is about to make the choice between a monetary benefit and the retention of the reputation of a reliable service provider, use of the designed tool affords rather objective instead still occurring intuitive making decisions in the airline disruption management.

\subsection{Outlook}

There is a significant opportunity for further research and comprehensive knowledge as, for example, on the following topics:

(1) An extension of DEVOTED employment in multiconnection flights, e.g. (i) multi in-bound flights to one out-bound flight, (ii) one in-bound flight to multi-outbound flights;
(2) If the time-component is incorporated into the modelling and evaluating process, the decision solutions and their consequences could be dynamically followed;

(3) If (more) actual delay costs occurring instead applied estimated or expected ones are included, the proposed tool could give more accurate/precise decision recommendations.

Open Access This article is distributed under the terms of the Creative Commons Attribution 4.0 International License (http:// creativecommons.org/licenses/by/4.0/), which permits unrestricted use, distribution, and reproduction in any medium, provided you give appropriate credit to the original author(s) and the source, provide a link to the Creative Commons license, and indicate if changes were made.

\section{References}

1. Martin JC, Roman C (2008) Airlines and their focus on cost control and productivity. EJTIR 8:117-136

2. Clausen, J., A. Larsen, and J. Larsen 2005 Disruption management in the airline industry - concepts, models and methods

3. Kohl, N., et al. 2004 Airline disruption management - perspectives, experiences and outlook, CEC

4. Castro, A.J.M. and E. Oliveira 2011 Airline operations control: a new concept for operations recovery nova science publishers: $p$. 61-97

5. Bratu S, Barnhart C (2006) Flight operations recovery: New approaches considering passenger recovery. J Sched 9(3):279-298

6. Doganis, R. 2002 Flying off course: the economics of international airlines. Third edition ed: British Library

7. Bratu S, Barnhart C (2004) An analysis of passenger delays using flight operations and passenger booking data. Air Traffic Control Q: Int J Eng Oper 13(1):1-27

8. Wu, C.-L. 2010 Airline operations and delay management: Ashgate Publishing Ltd

9. Jafari N, Zegordi SH (2010) The airline perturbation problem: considering disrupted passengers. Transp Plan Technol 33(2):203-220

10. Leick, R. 2007 Building airline passenger loyalty through an understanding of customer value, in school of engineering - College of Aeronautics, Cranfield University. p. 193

11. Gilbert DC (1996) Relationship marketing and airline loyalty schemes. Tour Manag 17(8):575-582

12. Sireli Y, Kauffmann P, Ozan E (2007) Integration of Kano's model into QFD for multiple product design. IEEE Trans Eng Manag 54(2):380-390

13. Castro, A.J.M. and E. Oliveira 2007 Quantifying quality operational costs in a multi-agent system for airline operations recovery. Int Rev on Comput Softw 4(4)

14. Bruce, P.J. 2011 Understanding Decision-making Process in Airline Operations Control: Ashgate 206

15. Maguire M (2001) Methods to support human-centred design. Academic Press 55:587-634

16. Lettovsky, L. 1997 Airline operations recovery: an optimization approach, Georgia Institute of Technology

17. Rabbani, F.F.R. 2004 Implementation of an airline recovery model in an event-based simulation, in Department of Aeronautics and Astronautics, Massachusetts Institute of Technology p 97 
18. Cook, A., G. Tanner, and S. Anderson 2004 Evaluating the true cost to airlines of one minute of airborne or ground delay: final report. Eurocontrol p 261

19. Cook, A., G. Tanner, and P. Enaud 2010 Quantifying airline delay costs - the balance between strategic and tactical costs, in 14th Air Transport Research Society (ATRS) World Conference: Porto, Portugal. p. 1-17

20. Cook, A., et al. 2013 E.02.06-POEM-D6.2-Final technical report: p. 135

21. Castro AJM, Oliveira E (2011) A new concept for disruption management in airline operations control. Proc Inst Mech Eng G: J Aerosp Eng 225(3):269-290
22. IATA 2007 Corporate air travel survey

23. Juga J, Juntunen J, Juntunen M (2012) Impact of service quality, image and relational aspects on satisfaction and loyalty in logistics outsourcing relationships. Int J Shipp Transp Logist 4(1):17-28

24. Suzuki Y (2000) The relationship between on-time performance and airline market share: a new approach. Elsevier Sci 36(2):139-154

25. Clarke MDD (1998) Irregular airline operations: a review of the state-of-the-practice in airline operations control centers. J Air Transp Manag 4(2):67-76

26. Taneja, NK. 2005 Fasten your seatbelt: the passenger is flying the plane: Ashgate Publishing Ltd 223 